\title{
Nycthemeral movements of wintering shorebirds reveal important differences in habitat uses of feeding areas and roosts
}

C. Jourdan, J. Fort, D. Pinaud, P. Delaporte, J. Gernigon, N. Lachaussée, J.-C. Lemesle, C. Pignon-Mussaud, P. Pineau, F. Robin, P. Rousseau, and P. Bocher

C. Jourdan, J. Fort, N. Lachaussée, C. Pignon-Mussaud, P. Pineau, and P. Bocher, Laboratory Littoral Environnement et Sociétés UMR LIENSs 7266 CNRS- La Rochelle University, La Rochelle, France. - D. Pinaud Centre d'Etudes Biologiques de Chizé (CEBC), UMR 7372, CNRS-La Rochelle Université, 79360, Villiers en Bois, France. - P. Delaporte and P. Rousseau, National Nature Reserve of Moëze-Oléron, LPO Ligue pour la Protection des Oiseaux, Plaisance, Saint-Froult, France. - J. Gernigon and J.-C. Lemesle, National Nature Reserve of Lileau des niges, LPO, Les Portes en Ré, France. - F. Robin, LPO, Fonderies Royales, Rochefort, France

Corresponding author: C. Jourdan-clement.jourdan1@univ-1r.fr

ORCID iD of the corresponding author: 0000-0002-5477-7494 


\begin{abstract}
Most shorebirds depend on coastal habitats for much of their life cycle. The quality and diversity of feeding areas during the wintering period directly condition their winter survival, subsequent migration, and breeding success. During their wintering in France, shorebirds use intertidal areas for feeding, both in daylight and at night, depending on the availability of mudflats during the tidal cycle. In this context, we studied whether the bar-tailed godwit (Limosa lapponica) shows contrasting foraging behaviors and distributions between day and night in response to differences in visual capacities, prey availability, potential predation risk, and human activities. We carried out a fine-scale GPS tracking of birds at one of their main wintering sites along the French Atlantic coast. We predicted smaller foraging home ranges at night because of limits for godwits to detect prey visually, suggesting more sediment probing and less movement. Godwits used the entire time window when they have access to intertidal areas, but they faithfully selected distinct diurnal and nocturnal feeding areas using a low number of patches. This variability in space use highlights differences in selection of habitats, such as seagrass beds selected by most of the tracked godwits by day and used much less at night. In addition, distinct feeding distributions of monitored birds revealed interindividual variability in habitat selection, even more by night, most likely to reduce intraspecific competition. We therefore urge greater consideration of the night distribution of birds, rarely evaluated in shorebirds studies, to define areas and habitats of importance to future management and conservation measures.
\end{abstract}

Keywords: Coastal ecology, coastal habitats, intertidal mudflats, GPS tracking, nocturnal foraging, Limosa lapponica 


\section{Introduction}

2 According to the principle of optimal foraging, animals tend to maximize their net energy intake per unit time (Stephens and Krebs 1986) and thus forage in the best conditions to catch maximal prey with minimal energy lost. In most birds, vision is the main sense used both day and night (Martin 2012). Therefore, the majority of bird species are active during daylight, that is, when visual conditions are best for foraging (Martin 1990). However, foraging may also be influenced by, for instance, predation risk, competition, food availability, weather conditions, and human disturbance, and birds have to adapt their behavior to devise the optimum strategy toward survival (McNamara and Houston 1980; Abrahams and Dill 1989).

In coastal shorebirds feeding in intertidal areas, the quality of wintering sites, and especially of feeding areas, directly affects their winter survival, subsequent migration, and breeding success (Pitelka 1979; Piersma et al. 1993; Gunnarsson et al. 2005; West et al. 2005; Gunnarsson et al. 2006; Morrison et al. 2007). The spatiotemporal distribution of birds in intertidal areas therefore depends on prey diversity and abundance (Kelsey and Hassall 1989; VanDusen et al. 2012) as well as their availability (Colwell and Landrum 1993) to maximize the rate of energy intake over the exposure period in such areas (van Gils et al. 2003; GossCustard et al. 2007; Quaintenne et al. 2010). Studies on wintering shorebird activity showed a tidal pattern of space use linked with the tidal effect on the availability of intertidal trophic resources (Puttick 1984; Colwell and Landrum 1993; Granadeiro et al. 2006). Thus, shorebirds wintering on sites subject to the tidal cycle will use intertidal foraging areas when available at low tides, that is, both during daylight and night (McNeil et al. 1992; McNeil and Rodriguez 1996). This sustained feeding behavior during nocturnal low tides could allow the birds to (1) benefit from better feeding opportunities (prey activity and availability), according to the preference hypothesis (Dugan 1981; Evans 1987; Mouritsen 1994), or (2) meet daily energetic requirements not satisfied in daylight, according to the supplementary hypothesis (McNeil and 
Rodriguez 1996; Smith et al. 1999; Sitters 2000). However, in addition to different diurnal and nocturnal foraging conditions, bird visual capacities, such as prey availability or predation risk (Dugan 1981; Evans 1987), could constrain bird foraging patterns and behaviors. Consequently, they should adjust their foraging activity, technique, and space use between daytime and nighttime (Mouritsen 1993; Rojas et al. 1999; Kuwae 2007). Species that can switch from sight to tactile feeding, such as the dunlin (Calidris alpina), the Eurasian oystercatcher (Haematopus ostralegus), the black-tailed godwit (Limosa limosa), or the Tringa species (Mouritsen 1994; McNeil and Rodriguez 1996; Lourenço et al. 2008) could take advantage of nocturnal feeding. Sight-feeding shorebirds could also benefit from night feeding because of the moonlight (McNeil et al. 1992) and/or physiological adaptations improving their nocturnal vision (Pienkowski 1983; Rojas et al. 1999) to maintain a high intake rate during nighttime (Pienkowski 1983; Lourenço et al. 2008). Furthermore, the higher activity and accessibility of prey at night in intertidal mudflats (McNeil et al. 1995; Esser et al. 2008), combined with the aforementioned bird capacities, could explain such an interest in nocturnal foraging behavior to satisfy wintering energetic requirements.

Both diurnal and nocturnal foraging areas are therefore important for wintering shorebirds. However, most studies focused on their daylight activity and distribution, disregarding possible important areas used only during nighttime yet also essential for adapted conservation and management measures to protect these vulnerable species. In that context, we studied the diurnal and nocturnal spatial distributions of the bar-tailed godwit (Limosa lapponica lapponica) wintering on Ré Island (Pertuis Charentais, Atlantic French coast), a site of national importance for the species. The population of L. l. lapponica is estimated at 120,000 (Delany et al. 2009), and France sees 5.8\% of wintering godwits, among which about $650(>1 \%$ of national numbers) are recorded on Ré Island in January (J-C. Lemesle, Pers. Com.). The bartailed godwit is characterized by increasing trends of the wintering population at the European 
51

52

scale (BirdLife International 2015), and its numbers have been stable in France in the last 12 years (Schmaltz et al. 2019). Nonetheless, large fluctuations of the population have been observed in recent decades in France, including significant decreases during the 1980s and 1990s (Triplet et al. 2010) likely due to degraded wintering habitats and increasing human disturbance (Goeldner-Gianella 2005; Delany et al. 2009; BirdLife International 2017). In this context, we tested the hypothesis that the bar-tailed godwit shows contrasting foraging behaviors and distributions between day and night. Indeed, visual capacities, prey availability, predation risk, and human activities are all factors influencing the behavior of birds, and their variability between day and night could lead to differences in their distribution. We predicted smaller foraging home ranges at night because of birds' difficulty in visually detecting prey (Turpie and Hockey 1993), suggesting more sediment probing and therefore less movement (Pienkowski 1983; Lourenço et al. 2008). To achieve these objectives, we conducted a finescale GPS tracking of wintering habitat use and investigated the birds' (1) spatial distribution and foraging home ranges, (2) feeding movements, (3) habitat selection, and (4) their variation between daytime and nighttime. 


\section{Methods}

\section{Study site}

Fieldwork was carried out in the Pertuis Charentais, which includes the largest area of intertidal mudflats on estuarine systems in France (Goeldner-Gianella 2005), during the wintering period (from November to March) of shorebirds in 2015-2016 and 2016-2017 (Fig. 1). We focused on Ré Island, one of the main wintering sites for bar-tailed godwits in the Pertuis Charentais. On Ré Island, godwits are known to roost in the former saltpans of the National Nature Reserve of Lilleau des Niges and use two main feeding areas on soft substrates (Aubouin 2014; Duijns et al. 2014). The first feeding site is a mudflat inside a semienclosed bay classified according to the Ramsar Convention since 2003, the "Fier d'Ars" (46²13'18"N; 1³0'29"W) (Fig. 1). A part of the "Fier d'Ars" (the western part of the bay and the high-tide roosts in saltmarshes) is also included in the Nature Reserve. The second main feeding site is "La Loge" $\left(46^{\circ} 14^{\prime} 25^{\prime \prime} \mathrm{N}\right.$; $\left.1^{\circ} 28^{\prime} 42^{\prime \prime}\right)$, a sandflat on the exposed coast north of the Island and where the foreshore remains uncovered by the tide for about four hours only, thus reducing food availability (Fig. 1). "La Loge" is part of the Ramsar labeled site "Marshes of the Fier d'Ars" but does not benefit from any protection status, and recreational activities on the beach in the summer, as well as in the winter to a lesser extent, are frequent during the day.

\section{Capturing and tracking godwits}

Bar-tailed godwits were captured using mist nets during nonmoonlight nights inside the Nature Reserve. Godwits were immediately marked with a metal ring and a unique color ring combination, and body mass (accuracy within $1.0 \mathrm{~g}$ ), wing length (nearest $1 \mathrm{~mm}$ ), tarsus length (nearest $0.5 \mathrm{~mm}$ ) and bill length (nearest $0.5 \mathrm{~mm}$ ) were measured using standard methods (Prater et al. 1977; Evans 1986). When possible, the sex (bill length: 69-90 mm for males and 86-110 mm for females; mass: $230-383 \mathrm{~g}$ for males and $280-455 \mathrm{~g}$ for females) and age (fringe 
of median covert feathers is pale with brown tips in juveniles, white in adults; primary flight feathers are worn in juveniles, new in adults) of individuals were determined (Pyle 2008; Demongin 2020). The heaviest godwits captured, which were all females, were fitted with a GPS-VHF logger (STERNA VHF-SRD with solar charger, Ecotone, Gdánsk, Poland; $35 \times 16$ $\times 10 \mathrm{~mm}, 7.5 \mathrm{~g}$ ) when the mass of the tag remained less than $3 \%$ of the bird body mass. In total, 15 individuals (11 in 2015 and 4 in 2016) were equipped with a GPS logger. Juvenile females, potentially not faithful to the study site during winter, were not selected. Tags (accuracy of \pm 10 m) were fixed on birds with a $2 \mathrm{~mm}$ Teflon harness (on the lower back) according to the "legloop" method (Mallory and Gilbert 2008) and were programmed to record positions every 30 minutes. Six of the 15 individuals provided a sufficient number of positions over the winter and were retained for analyses. Three individuals provided data during both winters, two others during winter 2015-2016, and a last one during winter 2016-2017. For individuals with two winter surveys, we retained the data of the winter with the best balance of GPS fixed numbers between day and night. Thus, we used the data of winter 2015-2016 for BTG01, BTG02, BTG04, and BTG05, and the data of winter 2016-2017 for BTG03 and BTG06. The monitoring period extended from November to March for four individuals and from December to March for the other two (Table 1). The data were stored and processed from a PostgreSQL/PostGIS database.

\section{Habitat mapping}

For each bird monitored, sediment core sampling was performed around the centroid of several feeding areas defined by GPS locations collected during the first two months after the birds were fitted with transmitters (see below for details). This sampling method, carried out on a grid of 9 cores spaced by 10 meters and arranged around the central reference point of the station, should describe the availability and quality of trophic resources (distribution and density of benthic macrofauna) at the feeding areas used by godwits. The samples were 
collected by foot at low tide according to methods described in Bocher et al. (2007) and Bijleveld et al. (2012). Each sample consisted of a $15 \mathrm{~cm}$ diameter sediment core $\left(0.01 \mathrm{~m}^{2}\right)$, with a depth of $15 \mathrm{~cm}$ (maximum depth reached by foraging birds according to mean bill length of females), sieved over a $1 \mathrm{~mm}$ mesh size on site. Annelids were immediately preserved in $70 \%$ ethanol, and mollusks were stored at $-20^{\circ} \mathrm{C}$ until sorted at the laboratory. Mudsnails (Hydrobia ulvae), a potentially small and abundant prey, were sampled through an additional core $\left(70 \mathrm{~mm}\right.$ diameter) of $0.0037 \mathrm{~m}^{2}$, to a depth of $5 \mathrm{~cm}$, and sieved in the laboratory over a 0.5 mm mesh. A larger sediment core sampling for mudsnails would be a time-consuming process. In the laboratory, the organisms were identified to the species level as often as possible, and mollusks were measured within a $0.1 \mathrm{~mm}$ accuracy.

Mean grain size $(\mathrm{mm})$ and percentage of silt (fraction $<63 \mu \mathrm{m}$ ) of a sediment core for each sampling station (depth of $5 \mathrm{~cm}$ ) was determined using a Malvern Mastersizer 2000 diffraction laser (particle sizes analyzed from 0.04 to $2,000 \mu \mathrm{m}$ ) to characterize the granulometry of the substrate. The results of the sediment's particle size characteristics helped define each sampling station in terms of habitat type and thus build a habitat map for the two study areas.

Finally, the benthic macrofauna data, sediment characteristics, and field observations allowed us to build a fine-scale map of intertidal habitat typology in the study site using the European Nature Information System (EUNIS) classification of coastal habitats as a reference (Bajjouk et al. 2015). Seagrass beds were delimitated on site using GPS Trimble GeoXH during summer 2012.

\section{Home ranges and habitat selection}

The estimation of the utilization distribution (UD), that is, the probability of finding each bird at any location (Calenge 2015), was used to analyze diurnal and nocturnal space use by godwits. Kernel density estimates (KDE) (Van Winkle 1975; Worton 1989) were used to describe UD 
(Laver and Kelly 2008) with the "kernelUD" function from the R package "adehabitatHR"

141 (Calenge 2015). The spatial distribution of bird locations and the corresponding time spent in an area are considered by KDE method to estimate the home ranges (at $95 \%$ isopleth) and core areas (at 50\% isopleth) of each individual (Worton 1989). To estimate the kernel home ranges, a compromise between the undersmoothing of least-square cross-validation (LSCV) and the over-smoothing of reference bandwidth (ad hoc) was used: a smoothing factor of $70 \%$ of the minimum reference value obtained by the "ad hoc" bandwidth (Kie et al. 2010; Schuler et al. 2014). Using a single smoothing factor $(\mathrm{h}=80)$, calculated on the set of GPS data and used to estimate bird kernels, allowed us to compare UDs between individuals. Considering the accuracy of the GPS positions ( $\pm 10 \mathrm{~m}$ ), the grid size was set to $20 \mathrm{~m}$. After estimating global UDs, the specific foraging distribution and resting distribution were computed. Field observations allowed to define a spatial delimitation on upper intertidal areas above which birds were mainly at rest and not foraging. Thus, foraging distribution was estimated from the GPS positions of birds located, at low tide, on intertidal areas below an elevation of $3.3 \mathrm{~m}$ relative to the hydrographic zero. In the same way, resting distribution was computed from the GPS distinguish diurnal and nocturnal positions and allowed for the computation of birds' foraging and resting distribution by differentiating day and night.

UDs were then used to investigate the importance of foraging habitats through habitat selection analysis. For this, we considered a second-order selection (design II), that is, a same availability of habitats for all birds and an analysis of habitat selection at the individual scale (Johnson 1980). A minimum convex polygon (MCP) of foraging points from all monitored birds provided an estimation of available foraging habitats for godwits. Individual kernel home ranges and the habitat typology of the study area were then superimposed to perform habitat 
165 selection analysis through Manly's selection ratios (Manly et al. 2002) and using the R package 166 "adehabitatHS" (Calenge 2011). We explored the interindividual variability of habitat selection 167 through an Eigen analysis of selection ratios (Calenge and Dufour 2006), a multifactorial 168 method. These analyses and other statistical tests (ANOVA, paired t-tests and chi-squared tests) 169 were performed with the software R (3.6.1). 


\section{Day and night feeding areas}

173

Godwits showed an extreme fidelity to their feeding grounds along the wintering period (from November to March), with a limited number of prospected areas per individual, both during daylight and night. The mean sizes of diurnal feeding home ranges (dFHR, kde 95\%) and diurnal feeding core areas (dFCA, kde 50\%) were $224 \pm 77$ ha (min-max: 125-321 ha) and 45 \pm 18 ha (22-68 ha), respectively (Table 1 , Fig. 2). The mean sizes of nocturnal feeding home ranges (nFHR, kde 95\%) and nocturnal feeding core areas (nFCA, kde 50\%) were, compared with diurnal ones, much smaller with $128 \pm 72$ ha (36-226 ha) and $23 \pm 12$ ha (8-34 ha), respectively $(\mathrm{dFCA} / \mathrm{nFCA}: \mathrm{t}=6.535, \mathrm{df}=5, \mathrm{p}$-value $=0.001 ; \mathrm{dFHR} / \mathrm{nFHR}: \mathrm{t}=9.0391, \mathrm{df}=5$, p-value $<0.001)$. In addition, the overlaps between diurnal and nocturnal home ranges were low at an individual scale (Table 1). The mean individual day-night overlap was $35 \pm 14 \%$ (min-max: 12\%-54\%) between dFHR and nFHR and $18 \pm 11 \%$ (min-max: 5\%-34\%) between dFCA and nFCA (Table 1).

\section{Rhythm of feeding activity}

The recorded bird foraging positions indicated that godwits could start foraging mainly between 2 and 3 hours before the low tide and 3 and 4 hours after the low tide, both during daylight and night (Fig. 3). From 2 hours before and 3 hours after low tide, birds spent about $95 \%-100 \%$ of their time on foraging areas during daylight and $90 \%-95 \%$ during the night except BTG05 with $80 \%-85 \%$ and $75 \%-80 \%$, respectively. The proportion of time spent on the foraging area during the ebb tide (c. 6 hours) increased continuously during daylight, from $5 \%-10 \%$ to $10 \%$ and $15 \%$ during the first 2 hours, to $50 \%$ during the third hour. At night, godwits spent a steady proportion of time on the foraging area (around 0\%-5\%) during the first 2 hours of the ebbing tide but suddenly went up to $40 \%$ between the third and fourth hours. On average, godwits 
therefore joined the foraging areas earlier by daylight, spending significantly more time on intertidal areas during the day than at night during the fourth and third hour before the low tide, with an average of $11 \%$ and $12 \%$ of additional time (Fig. 3). Similarly, godwits remained longer on mudflats at the end of the daylight rising tide compared to the nighttime, with $6 \%$ and $7 \%$ additional time spent on the foraging areas over the third and fourth hour after low tide, respectively, although differences were not significant (Fig. 3). Finally, considering the entire tidal cycle (from -6 hours to 6 hours around low tide), bar-tailed godwits spent a higher percent of their time on foraging grounds by day than by night (paired t-test: $\mathrm{t}=5.35, \mathrm{df}=5, \mathrm{p}$-value $=$ $0.003)$.

\section{Daylight and night local movements}

The distances measured between the two successive recorded locations on the feeding areas were shorter at night than during daylight for all individuals ( $\mathrm{t}$-value $=-3.82$, p-value $<0.001$; meanNight $=298 \mathrm{~m}$, meanDay $=411 \mathrm{~m})$. In proportion, godwits systematically made more small movements (or displacements) at night than during the daylight. For nocturnal movements, 0-50 m distance class was the most represented, and most direct distances recorded between two consecutive locations (30 min) were less than $100 \mathrm{~m}$ (Fig. 4). By day, most distances between points on the feeding area exceeded $100 \mathrm{~m}$, and the most represented distance class was $100-150 \mathrm{~m}$ (Fig. 4).

\section{Habitat diversity and structure}

In total, 11 locations, as potential feeding habitats, were identified in the intertidal areas of the study site (Fig. 5). The "Fier d'Ars" area included a large diversity of habitats, with a clear dominance of seagrass beds (A2.6111 - 27\% of the total intertidal site surface), bare mudflat (A2.313-19\%), and oyster parks (A2.32-8\%) on the muddy foreshore at the center of the bay (Fig 5.b). Habitat A2.6111 was characterized by a fine muddy sand substrate with an abundance of Zostera noltei and infaunal species dominated by polychaetes (Scoloplos armiger 
and Arenaria marina), oligochaetes, and mollusks (Cerestoderma edule, Macoma balthica, and Hydrobia ulvae). Habitat A2.313 corresponded to a littoral sandy mud, mainly characterized by polychaetes (Hediste diversicolor) and bivalves (M. balthica and Scrobicularia plana). A2.32 was a muddy substrate mainly characterized by a low diversity of polychaetes and oligochaetes, covered with artificial oyster grow-out tables. Another habitat well represented in the "Fier d'Ars" was an intertidal muddy sandflat dominated by polychaetes (Eteone longa, S. armiger) and capitellidae combined with the bivalve C. edule (A2.242-6\%). Saltmarsh creeks in the A2.5 coastal saltmarshes (A2.325 - 17\%) surrounded the muddy bay while rocky elements, that is, bedrock and boulders dominated by mussels and/or barnacle communities (A1.11 - 1\%) and habitats with littoral rock features (A1.41 - 6\%) characterized the bay entrance.

The site of "La Loge" contained specific habitats not found on "Fier d'Ars" with clearly sandy characteristics (Fig. 5.c). These habitats were A2.221 (17\% of the total study intertidal site surface), a barren coarse sandbank that can only shelter an extremely small number of oligochaetes because of the constant mobility of the coarse sediment, and A2.231 (38\%), a littoral fine sand dominated by polychaetes including Nephtys cirrosa and S. armiger. The northern part of "La Loge" was described by habitats A1.41 (composed of rocky elements and sheltering littoral rockpool communities $-21 \%$ ) and A2.242 (dominated by polychaetes $E$. longa, S. armiger, and capitellidae, combined with the bivalve C. edule-18\%).

\section{Foraging habitat selection}

During daylight, godwits did not use available foraging habitats randomly but showed a significant habitat selection, both at an individual scale $\left(\chi^{2}=47563.98, \mathrm{df}=9.0, \mathrm{p}<0.001\right)$ and when combining the six birds monitored $\left(\chi^{2}=51039.79, \mathrm{df}=54.0, \mathrm{p}<0.001\right)$. In the diurnal feeding core areas, the seagrass bed habitat (A2.6111) was selected by four godwits (BT01, BTG02, BTG03, and BTG04) (Fig. 6). For BTG05 and BTG06, the most represented habitats were the sandflat dominated by C. edule and polychaetes (A2.242) and the mudflat dominated 
by $H$. diversicolor and S. plana (A2.313), respectively. Habitat A2.313 was also a prevailing habitat in the core feeding areas of BTG02 and BTG05. Hence, habitat A2.6111 appeared preferentially used by godwits on average, followed by A2.242 and A2.313 (global selection ratios $>$ 1) (Fig. 7). Conversely, habitat A1.31 (fucoids on sheltered shores) was globally avoided by the studied birds (global selection ratios $<1$ ) although standard errors indicate their marginal use by some birds. The six remaining habitats were clearly avoided (global selection ratios and $\mathrm{SE}<1)$.

During nighttime, the birds also showed significant habitat selection when considering all birds $\left(\chi^{2}=38081.9, \mathrm{df}=54.0, \mathrm{p}<0.001\right)$ and individuals independently $\left(\chi^{2}=31774.09, \mathrm{df}=9.0, \mathrm{p}\right.$ $<0.001)$. Habitats in the nocturnal feeding core areas were more specific, with strong individual patterns. The feeding core areas of BTG01, BTG02, BTG03, BTG04, BTG05, and BTG06 were mainly composed of habitats of oyster parks (A2.32), bare mudflat (A2.313), intertidal muddy sandflat (A2.242), littoral fine sand (A2.231), bare mudflat (A2.313), and seagrass beds (A2.6111), respectively, highlighting a strong interindividual variability (Fig. 6). This observation was confirmed by the result of the Manly selectivity measure, which did not allow a clear identification of a habitat preferentially used by the six birds. Indeed, habitats of littoral fine sand (A2.231), intertidal muddy sandflat (A2.242), bare mudflat (A2.313), oyster parks (A2.32), and seagrass beds (A2.6111) all appeared selected (global selection ratios $>1$ ) but with large standard errors that well illustrate the nonidentical use of habitats by all birds $\left(\chi^{2}=\right.$ 941.584; $\mathrm{df}=45.0 ; \mathrm{p}<0.001)($ Fig. 7). Although seagrass beds (A2.6111) remain globally the most selected habitat at night (Fig. 7), we note that all individuals showed a significant decrease of its use between day and night, with a proportion decreasing from an average of $48 \%$ to $19 \%$, except BTG06, which showed an opposite trend (Fig. 6).

The Eigen analysis emphasized these differences between diurnal and nocturnal habitat selection. During daytime, the reported positions of four individuals (BTG01, BTG02, BTG03, 
and BTG04) in the space described by habitats highlighted their preferential use of seagrass beds (A2.6111) (Supplementary Material Fig. S1). The other two birds stood out from this first group, with BTG06 clearly selecting the sandflat habitat dominated by C. edule and polychaetes (A2.242) and BTG05 in an intermediate position between A2.6111 and A2.242. At night, each individual selected a specific foraging habitat with five different habitats, thus preferentially used by godwits at night (A2.242, A2.231, A2.313, A2.6111, and A2.32).

\section{Roost selection}

Godwits' use of roosts differed markedly between day and night. The number of roosts used by individuals was not different between day and night, with one to three main roosts according to the estimation of roost core areas (isopleth 50) (Fig. 8). However, the location clearly varied between diurnal and nocturnal stages with a mean overlapping rate of $32 \%$ for roosting home ranges (RHRs) and 8\% for roosting core areas (RCAs) (Supplementary Material Table S1). By day, during high neap tide, birds preferentially roosted on the upper foreshore and used less significantly the saltpan roosts beyond dikes. At night, individuals clearly selected the saltpans of the Nature Reserve as roosts and avoided free intertidal areas during high neap tide. During spring tide, they could not stay on flooded intertidal areas and returned on saltpan roosts either by day or night. 


\section{Discussion}

By analyzing the nycthemeral use of habitats by wintering bar-tailed godwits at an extremely fine spatial scale, the present study revealed distinct foraging activities in shorebirds between day and night. Previous studies showed that shorebirds could use different feeding and roosting areas depending on the time of day and according to predation risk, disturbance, and density/activity of preys (Burton and Armitage 2005; Piersma et al. 2006). Here, we went further and showed that bar-tailed godwits faithfully selected distinct diurnal and nocturnal feeding areas using a low number of main feeding patches (CA), both during daylight and nighttime, with a relatively small feeding area by individuals. Moreover, birds moved less when prospecting at night, resulting in smaller nocturnal feeding home ranges. This variability in space use underlined differences in habitat selection, such as seagrass beds strongly selected by most of the tracked godwits by day and much less used at night. In addition, the distinct feeding distributions of the monitored females revealed interindividual variability in habitat selection. We noted that all our tracked birds were females, and there could be large differences in diet and patterns of space use between males and females during day and night.

Our study highlights that bar-tailed godwits spent as much time on feeding areas at night as during the day, devoting most of it to feeding activities from two hours before to three hours after low tide, that is, during the entire time window of mudflat availability. As observed in black-tailed godwits (Lourenço et al. 2008), this result highlights the importance of nocturnal feeding in the acquisition of daily energy needs by wintering bar-tailed godwits. Night foraging activity has been reported in most shorebird species wintering on tidal coasts although the relative importance of nocturnal activity depends on the species (Dugan 1981; McNeil and Rodriguez 1996). Many species favor feeding activity during the day, with visual capabilities allowing for higher intake rate and consequently providing the major part of the daily energy needs for birds (Dodd and Colwell 1996; Kam et al. 2004; Lourenço et al. 2008). Night foraging 
was therefore mainly considered as "supplementary" in previous studies, that is, used when diurnal prey intake is not enough to offset the increased energy demands of less favorable wintering conditions (McNeil and Rodriguez 1996; Smith et al. 1999; Sitters 2000). However, some shorebirds could fill a significant part of their energy requirements during the night (Turpie and Hockey 1993; Lourenço et al. 2008) because of physiological adaptations such as better nocturnal vision for Charadriidae (high rod-cone ratio in the eyes) (De Azuje et al. 1993; Rojas et al. 1999) or higher tactile sensitivity for Scolopacidae as in godwits (Cunningham et al. 2013), which facilitate nocturnal foraging.

In our study, the space used by wintering godwits differed between day and night, both during feeding and resting periods, as reported for other shorebirds in previous studies (Rompré and McNeil 1996; Piersma et al. 2006; Rogers et al. 2006). Birds were highly faithful to their daylight feeding grounds, with extremely restricted feeding core areas recorded over the winter. Their nocturnal feeding core areas were even more restricted and mostly spatially distinct from the daytime ones. These results contrast with the observations of Burton and Armitage (2005) on redshanks (Tringa tetanus), which also used separate diurnal and nocturnal foraging areas but with larger core areas and home ranges at night. In addition, the distinct distributions of bartailed godwits between day and night were associated with a change in habitat selection, notably with a strong decrease in the use of seagrass beds at night, as well as an increased use of oyster parks and sandflats. Various factors that we consider below, mainly related to the characteristics of wintering habitats, could explain these differences in space use between day and night.

Contrary to studies that highlighted an avoidance of nearshore areas by shorebirds during their nocturnal foraging in response to increased predation risks (Sitters et al. 2001; Burton and Armitage 2005; Piersma et al. 2006), we did not find that upper intertidal areas were less used by godwits at night. Conversely, a portion of monitored birds tended to focus on strategic points of the upper foreshore during nocturnal feeding, near anthropogenic illuminations. Studies 
highlighted a positive effect of artificial light on the nocturnal foraging of shorebirds by recreating full-moon conditions across the nearby intertidal areas that allow birds to maintain a sight-based foraging behavior at night and improve their prey intake rate (Santos et al. 2010; Dwyer et al. 2013). On Ré Island, public lighting points at the edge of the bay increase the level of ambient light across mudflat areas and could attract birds by allowing them to feed by sight (Lourenço et al. 2008; Santos et al. 2010).

Recreational and harvesting activities represent another form of disturbance related to anthropogenic activities, which has already been shown to affect the habitat use and foraging activity of wintering or migrating shorebirds (Lafferty 2001; Colwell et al. 2003; Navedo and Masero 2007; Burger and Niles 2013). For instance, studies emphasized that recreational activities on the foreshore, as well as shellfish harvesting activities, could induce a reduction of foraging time, flight behavior, or even a complete avoidance of the disturbed foraging areas (De Boer and Longamane 1996; Thomas et al. 2003; Navedo and Masero 2007; Burger and Niles 2013). This pattern is what we observed for some godwits on Ré Island, which avoided oyster parks (A2.32) and beaches (A2.231) during daytime while they commonly used these habitats at night. With a high predominance of polychaetes in the macrobenthic community, these habitats constitute attractive feeding areas for godwits, but the presence of oyster farmers, shell fishers, and walkers during the day constitutes a significant level of disturbance (Burton and Armitage 2005; Dias et al. 2008).

Contrasting foraging methods between day and night were also found to affect the spatial distribution of shorebirds. For instance, Mouritsen (1993) found that the dunlin (C. alpina) switched from visual feeding during the day to tactile feeding during the night, as did blacktailed godwits which showed a higher rate of stitches and sweeps at night and a majority of pecks during the day (Lourenço et al. 2008). Generally, the bill of the Scolopacidae species benefits from a high number of touch-sensitive nerve endings which favors tactile feeding (De 
Azuaje et al. 1993). Hence, we can assume that bar-tailed godwits switch from sight feeding during the day to probing at night and, as observed in dunlins (C. alpina) by Mouritsen (Mouritsen 1994), this change in behavior may induce the use of distinct feeding habitats based on prey availability. This could be related to the dominance of polychaetes, more active and likely more available at night (Last and Olive 2004; Kuwae 2007) in habitats A2.32 and A2.231, which could explain the nocturnal use of these habitats by godwits. We did not have available data to compare diurnal and nocturnal prey density, but studies underlined that polychaete worms, the favored preys of bar-tailed godwits (Duijns et al. 2013), may be closer to the sediment surface at night (McNeil et al. 1992; Esser et al. 2008). Such a density of prey available in the top layer of the sediment could explain the nocturnal preference of polychaetedominated habitats by godwits, as observed in dunlins and redshanks (Mouritsen 1994; Burton and Armitage 2005). Beyond their influence on the location of godwits' feeding areas, the differences in prey availability and foraging methods between day and night also seemed to affect the size of foraging areas.

On night foraging sites, higher prey availability could lead to better intake rates (Zharikov and Skilleter 2003), resulting in an area-restricted search for tactile predators through increased spatial turning rates (Dias et al. 2009). Godwits could thus use sinuous low-speed searches in more profitable patches at night (Nolet and Mooij 2002) and prefer faster direct searches with more step rates during the day as observed in black-tailed godwits (Lourenço et al. 2008). This pattern of feeding behavior could explain the differences observed in our study in the distances separating two successive foraging locations between day and night.

At high tide, results showed marked differences in the use of roosts between day and night during neap and spring tides. Indeed, at daytime, godwits selected upper mudflat roosts as soon as they were available, that is, during neap tides. However, at night, birds always used saltpans in whatever tidal heights. In a previous study based on daytime observations, Rosa et al. (2006) 
showed that wintering shorebirds, including bar-tailed godwits, preferentially select mudflats to roost, and move to saltpan roosts when the upper foreshore became unavailable during highest tides. This study also highlighted the effect of both raptor presence, higher in saltpans than in mudflats, and visibility, lower in saltpans, on daytime shorebird roost choice (Rosa et al. 2006). Others studies reported the anti-predator strategy of shorebirds avoiding some specific roosting areas by nighttime because of higher predation risks (Hilton et al. 1999; Rogers et al. 2006). Hence, in addition to their availability, the roost choice by shorebirds between day and night in the present study could be influenced by the predation risk (Handel and Gill 1992; Rohweder 2001). Birds would favor mudflats at day, less prone to overflying raptors and offering better visibility of approaching predators (Rosa et al. 2006), and saltpans at night, with a water barrier against nocturnal predators such as foxes or mustelids (Cramp et al. 1983; Sitters et al. 2001). Further studies are nonetheless needed to validate this hypothesis and better explain the pattern of use of roost sites on Ré Island, including the monitoring of predator activities.

Our results showed that all monitored bar-tailed godwits used the entire time window during which they have access to foraging grounds, both during the day and the night. Nocturnal foraging thus appears crucial along the winter to allow godwits to meet their daily energy requirements and is not only a "supplement" for diurnal foraging. However, nocturnal foraging is probably not preferential since we did not observe more use of feeding areas at night than during the day. We hypothesize that differences in biotic and abiotic environmental conditions (human disturbance, predation risk, feeding methods, and prey availability) between day and night all together incite birds to develop specific feeding strategies and behaviors, including the selection of contrasting habitats. Bar-tailed godwits also tended to specialize in their habitat use and thus in prey at an individual scale, even more by night, most likely to reduce intraspecific competition. Roost choice also depended on the time of day. The visibility of approaching 
predators and proximity to feeding sites, when possible, seemed to be important to the choice

414 of daytime roosts. Finally, these results provide an important knowledge of the nonbreeding

415 survival strategies of bar-tailed godwits on the French Atlantic coast. We therefore urge greater

416 consideration of the night distribution of birds, rarely evaluated in shorebird studies, to define

417 areas and habitats of importance in management and conservation. The day-night connectivity

418 in shorebirds' space use needs to be integrated into all spatial management plans where human

419 activities can deal with natural protected areas or their proximities.

420 Acknowledgments - We thank Jérôme Jourde for his help in determining the benthic

421 macrofauna, Tania Damany and Sébastien Comarmond for their help with sample processing,

422 and Françoise Amélineau and Chloé Tanton for their help during bird capture/marking sessions.

423 We also thank all the volunteers who participated in bird captures and sediment sampling. This

424 work has been supported by the ECONAT project funded by the Contrat de Plan Etat-Région

425 and the CNRS and the European Regional Development Fund (QUALIDRIS project). This

426 work was also funded by the ANR Pampas (ANR-18 CE32-0006) and the Ligue pour la

427 Protection des Oiseaux. We thank Christine Dupuy and Christel Lefrançois for the logistic

428 support. All work adheres to the legal requirements of the countries in which it was carried out 429 and meets ethical and animal welfare guidelines. 
432

433

434

435

436

437

438

439

440

441

442

443

444

445

446

447

448

449

450

451

452

453

454

455

456

457

458

459

460

461

462

463

464

465

466

467

468

469

470

471

472

473

474

475

476

477

478

Abrahams, M. V., and L. M. Dill. 1989. A determination of the energetic equivalence of the risk of predation. Ecology 70: 999-1007. https://doi.org/10.2307/1941368.

Aubouin, Naïs. 2014. Etude de la distribution et des stratégies de survie hivernale de populations migratrices d'oiseaux limicoles en vue d'actions de conservation en région Poitou Charentes: exemple de la Barge rousse Limosa lapponica. Msc Thesis $64 \mathrm{p}$.

De Azuaje, L. M. R., S. Tai, and R. McNeil. 1993. Comparison of rod/cone ratio in three species of shorebirds having different nocturnal foraging strategies. Auk: 141-145.

Bajjouk, T., B. Guillaumont, N. Michez, B. Thouin, C. Croguennec, J. Populus, J. LouvelGlaser, et al. 2015. Classification EUNIS, Système d'information européen sur la nature: Traduction française des habitats benthiques des Régions Atlantique et Méditerranée. Vol. 1. Habitats Littoraux.

Bijleveld, A. I., J. A. van Gils, J. van der Meer, A. Dekinga, C. Kraan, H. W. van der Veer, and T. Piersma. 2012. Designing a benthic monitoring programme with multiple conflicting objectives. Methods in Ecology and Evolution 3: 526-536. https://doi.org/10.1111/j.2041-210X.2012.00192.x.

BirdLife International. 2015. European red list of birds.

BirdLife International. 2017. Limosa lapponica (amended version of 2016 assessment). The IUCN Red List of Threatened Species 2017.

Bocher, P., T. Piersma, A. Dekinga, C. Kraan, M. G Yates, T. Guyot, E. Folmer, and G. Radenac. 2007. Site-and species-specific distribution patterns of molluscs at five intertidal soft-sediment areas in northwest Europe during a single winter. Marine Biology 151: 577-594. https://doi.org/10.1007/s00227-006-0500-4.

De Boer, W. F., and F. A. Longamane. 1996. The exploitation of intertidal food resources in Inhaca Bay, Mozambique, by shorebirds and humans. Biological Conservation 78: 295-303. https://doi.org/10.1016/S0006-3207(96)00050-X.

Burger, J., and L. Niles. 2013. Shorebirds and stakeholders: Effects of beach closure and human activities on shorebirds at a New Jersey coastal beach. Urban Ecosystems 16: 657-673. https://doi.org/10.1007/s11252-012-0269-9.

Burton, N. H. K., and M. J. S. Armitage. 2005. Differences in the diurnal and nocturnal use of intertidal feeding grounds by Redshank Tringa totanus. Bird Study 52: 120-128. https://doi.org/10.1080/00063650509461381.

Calenge, C., and A. B. Dufour. 2006. Eigenanalysis of selection ratios from animal radiotracking data. Ecology 87: 2349-2355. https://doi.org/10.1890/00129658(2006)87[2349:EOSRFA]2.0.CO;2.

Calenge, C. 2011. Exploratory analysis of the habitat selection by the wildlife in R: the adehabitatHS Package. Office national de la chasse et de la faune sauvage, Saint Benoist, 78610.

Calenge, C. 2015. Home range estimation in R: the adehabitatHR package. Office national de la classe et de la faune sauvage: Saint Benoist, Auffargis, France.

Colwell, M. A., T. Danufsky, N. W. Fox-Fernandez, J. E. Roth, and J. R. Conklin. 2003. Variation in shorebird use of diurnal, high-tide roosts: How consistently are roosts used? Waterbirds 26: 484-493. https://doi.org/10.1675/15244695(2003)026[0484:VISUOD]2.0.CO;2.

Colwell, M. A., and S. L. Landrum. 1993. Nonrandom shorebird distribution and fine-scale variation in prey abundance. The Condor 95: 94-103. https://doi.org/10.2307/1369390. 
Cramp, S., K. E. L. Simmons, D. C. Brooks, N. J. Collar, E. Dunn, R. Gillmor, P. a. D. Hollom, et al. 1983. Handbook of the birds of Europe, the Middle East and North Africa. The birds of the Western Palearctic: 3. Waders to gulls.

Cunningham, S. J., J. R. Corfield, A. N. Iwaniuk, I. Castro, M. R. Alley, T. R. Birkhead, and S. Parsons. 2013. The Anatomy of the bill Tip of Kiwi and Associated Somatosensory Regions of the Brain: Comparisons with Shorebirds. PloS One 8. Public Library of Science: e80036. https://doi.org/10.1371/journal.pone.0080036.

Delany, S., D. Scott, T. Dodman, and D. Stroud. 2009. The Wader atlas: An atlas of Wader populations in Africa and Western Eurasia.

Demongin, L. 2020. Guide d'identification des oiseaux en main: Les 250 espèces les plus baguées en France: identification, mensurations, variations géographiques, mue, sexe et âge. L. Demongin.

Dias, M. P., J. P. Granadeiro, and J. M. Palmeirim. 2009. Searching behaviour of foraging waders: Does feeding success influence their walking? Animal Behaviour 77: 12031209. https://doi.org/10.1016/j.anbehav.2009.02.002.

Dias, M. P., F. Peste, J. P. Granadeiro, and J. M. Palmeirim. 2008. Does traditional shellfishing affect foraging by waders? The case of the Tagus estuary (Portugal). Acta Oecologica 33: 188-196. https://doi.org/10.1016/j.actao.2007.10.005.

Dodd, S. L., and M. A. Colwell. 1996. Seasonal variation in diurnal and nocturnal distributions of nonbreeding shorebirds at North Humboldt Bay, California. The Condor 98: 196-207.

Dugan, P. J. 1981. The importance of nocturnal foraging in shorebirds: A consequence of increased invertebrate prey activity. In Feeding and Survival Srategies of Estuarine Organisms, ed. N. V. Jones and W. J. Wolff, 251-260. Boston, MA: Springer US. https://doi.org/10.1007/978-1-4613-3318-0_19.

Duijns, S., N. A. Hidayati, and T. Piersma. 2013. Bar-tailed godwits Limosa l. lapponica eat polychaete worms wherever they winter in Europe. Bird Study 60: 509-517. https://doi.org/10.1080/00063657.2013.836153.

Duijns, S., J. A. Van Gils, B. Spaans, J. ten Horn, M. Brugge, and T. Piersma. 2014. Sexspecific winter distribution in a sexually dimorphic shorebird is explained by resource partitioning. Ecology and Evolution 4: 4009-4018. https://doi.org/10.1002/ece3.1213.

Dwyer, R. G., S. Bearhop, H. A. Campbell, and D. M. Bryant. 2013. Shedding light on light: benefits of anthropogenic illumination to a nocturnally foraging shorebird. Journal of Animal Ecology 82: 478-485. https://doi.org/10.1111/1365-2656.12012.

Esser, W., S. Vöge, and K.-M. Exo. 2008. Day-night activity of intertidal invertebrates and methods to estimate prey accessibility for shorebirds. Senckenbergiana maritima 38 : 115-122. https://doi.org/10.1007/BF03055286.

Evans, A. 1987. Relative availability of the prey of wading birds by day and by night. Marine Ecology Progress Series 37: 103-107.

Evans, P. R. 1986. Correct measurement of the wing-length of waders. Wader Study Group Bull 48:11.

van Gils, Jan A., I. W. Schenk, O. Bos, and T. Piersma. 2003. Incompletely informed shorebirds that face a digestive constraint maximize net energy gain when exploiting patches. The American Naturalist 161: 777-793. https://doi.org/10.1086/374205.

Goeldner-Gianella, L. 2005. Verger (F.) - Marais maritimes et estuaires du littoral français. Paris, Belin, 2005, 335 p. Norois. Environnement, aménagement, société: 138-139.

Goss-Custard, J. D., A. D. West, M. G. Yates, R. W. G. Caldow, R. A. Stillman, L. Bardsley, J. Castilla, et al. 2007. Intake rates and the functional response in shorebirds (Charadriiformes) eating macro-invertebrates. Biological Reviews 81: 501-529. https://doi.org/10.1111/j.1469-185X.2006.tb00216.x. 
Granadeiro, J. P., M. P. Dias, R. C. Martins, and J. M. Palmeirim. 2006. Variation in numbers and behaviour of waders during the tidal cycle: Implications for the use of estuarine sediment flats. Acta Oecologica 29: 293-300. https://doi.org/10.1016/j.actao.2005.11.008.

Gunnarsson, T. G., J. A. Gill, J. Newton, P. M. Potts, and W. J. Sutherland. 2005. Seasonal matching of habitat quality and fitness in a migratory bird. Proceedings of the Royal Society B: Biological Sciences 272: 2319-2323. https://doi.org/10.1098/rspb.2005.3214.

Gunnarsson, T. G., J. A. Gill, P. W. Atkinson, G. Gélinaud, P. M. Potts, R. E. Croger, G. A. Gudmundsson, G. F. Appleton, and W. J. Sutherland. 2006. Population-scale drivers of individual arrival times in migratory birds. Journal of Animal Ecology 75: 11191127.

Handel, C. M., and R. E. Gill. 1992. Roosting behavior of premigratory dunlins (Calidris alpina). The Auk 109: 57-72. https://doi.org/10.2307/4088266.

Hilton, G. M., G. D. Ruxton, and W. Cresswell. 1999. Choice of foraging area with respect to predation risk in redshanks: The effects of weather and predator activity. Oikos 87: 295-302. https://doi.org/10.2307/3546744.

Johnson, D. H. 1980. The comparison of usage and availability measurements for evaluating resource preference. Ecology 61: 65-71. https://doi.org/10.2307/1937156.

Kam, J. van de, B. Ens, T. Piersma, and L. Zwarts. 2004. Shorebirds: An Illustrated Behavioural Ecology. Brill.

Kelsey, M. G., and M. Hassall. 1989. Patch selection by dunlin on a heterogeneous mudflat. Ornis Scandinavica (Scandinavian Journal of Ornithology) 20: 250-254. https://doi.org/10.2307/3676488.

Kie, J. G., J. Matthiopoulos, J. Fieberg, R. A. Powell, F. Cagnacci, M. S. Mitchell, J.-M. Gaillard, and P. R. Moorcroft. 2010. The home-range concept: Are traditional estimators still relevant with modern telemetry technology? Philosophical Transactions of the Royal Society B: Biological Sciences 365: 2221-2231. https://doi.org/10.1098/rstb.2010.0093.

Kuwae, T. 2007. Diurnal and nocturnal feeding rate in Kentish plovers Charadrius alexandrinus on an intertidal flat as recorded by telescopic video systems. Marine Biology 151: 663-673.

Lafferty, K. D. 2001. Birds at a Southern California beach: Seasonality, habitat use and disturbance by human activity. Biodiversity \& Conservation 10: 1949-1962.

Last, K. S., and P. J. W. Olive. 2004. Interaction between photoperiod and an endogenous seasonal factor in influencing the diel locomotor activity of the benthic polychaete Nereis virens Sars. The Biological Bulletin 206: 103-112. https://doi.org/10.2307/1543541.

Laver, P. N., and M. J. Kelly. 2008. A critical review of home range studies. Journal of Wildlife Management 72: 290-298. https://doi.org/10.2193/2005-589.

Lourenço, P. M., A. Silva, C. D. Santos, A. C. Miranda, J. P. Granadeiro, and J. M. Palmeirim. 2008. The energetic importance of night foraging for waders wintering in a temperate estuary. Acta Oecologica 34: 122-129. https://doi.org/10.1016/j.actao.2008.04.005.

Mallory, M. L., and C. D. Gilbert. 2008. Leg-loop harness design for attaching external transmitters to seabirds. Marine Ornithology 36: 183-188.

Manly, B. F., L. McDonald, D. L. Thomas, T. L. McDonald, and W. P. Erickson. 2002. Resource selection by animals: Statistical design and analysis for field studies. Springer Science \& Business Media. Springer Science \& Business Media.

Martin, G. 1990. Birds by Night. Poyser. 
Martin, G. R. 2012. Through birds' eyes: Insights into avian sensory ecology. Journal of Ornithology 153: 23-48. https://doi.org/10.1007/s10336-011-0771-5.

McNamara, J., and A. Houston. 1980. The application of statistical decision theory to animal behaviour. Journal of Theoretical Biology 85: 673-690. https://doi.org/10.1016/00225193(80)90265-9.

McNeil, R., O. Díaz Díaz, I. Liñero A., and J. R. Rodríguez S. 1995. Day- and night-time prey availability for waterbirds in a tropical lagoon. Canadian Journal of Zoology 73: 869878. https://doi.org/10.1139/z95-102.

McNeil, R., P. Drapeau, and J. D. Goss-Custard. 1992. The occurrence and adaptive significance of nocturnal habits in waterfowl. Biological Reviews 67: 381-419. https://doi.org/10.1111/j.1469-185X.1992.tb01188.x.

McNeil, R., and J. R. Rodriguez. 1996. Nocturnal foraging in shorebirds. International Wader Studies 8: 114-121.

Morrison, G., N. C. Davidson, and J. Wilson. 2007. Survival of the fattest: Body stores on migration and survival in red knots Calidris canutus islandica. Journal of Avian Biology 38: 479-487.

Mouritsen, K. N. 1993. Diurnal and nocturnal prey detection by dunlins Calidris alpina. Bird Study 40: 212-215. https://doi.org/10.1080/00063659309477185.

Mouritsen, K. N. 1994. Day and night feeding in dunlins Calidris alpina: Choice of habitat, foraging technique and prey. Journal of Avian Biology 25: 55-62. https://doi.org/10.2307/3677294.

Navedo, J. G., and J. A. Masero. 2007. Measuring potential negative effects of traditional harvesting practices on waterbirds: A case study with migrating curlews. Animal Conservation 10: 88-94. https://doi.org/10.1111/j.1469-1795.2006.00076.x.

Nolet, B. A., and W. M. Mooij. 2002. Search paths of swans foraging on spatially autocorrelated tubers. Journal of Animal Ecology 71: 451-462. https://doi.org/10.1046/j.1365-2656.2002.00610.x.

Pienkowski, M. W. 1983. Changes in the foraging pattern of plovers in relation to environmental factors. Animal Behaviour 31: 244-264. https://doi.org/10.1016/S00033472(83)80195-X.

Piersma, T., R. E. Gill, P. de Goeij, A. Dekinga, M. L. Shepherd, D. Ruthrauff, and L. Tibbitts. 2006. Shorebird avoidance of nearshore feeding and roosting areas at night correlates with presence of a nocturnal avian predator. Bulletin-Wader Study Group 109: 73-76.

Piersma, T., P. de Goeij, and I. Tulp. 1993. An evaluation of intertidal feeding habitats from a shorebird perspective: Towards relevant comparisons between temperate and tropical mudflats. Netherlands Journal of Sea Research 31: 503-512. https://doi.org/10.1016/0077-7579(93)90062-W.

Pitelka, F. A. 1979. Shorebirds in marine environments. Cooper Ornithological Society.

Prater, A. J., J. H. Marchant, and J. Vourinen. 1977. Guide to the identification and ageing of Holartcic waders. Tring, Herts. BTO Guide No. 17.

Puttick, G. M. 1984. Foraging and activity patterns in wintering shorebirds. Behavior of Marine Animals: Current Perspectives in Research.

Pyle, P. 2008. Identification guide to North America birds: Part II. Slate Creek Press.

Quaintenne, G., J. A. van Gils, P. Bocher, A. Dekinga, and T. Piersma. 2010. Diet selection in a molluscivore shorebird across Western Europe: Does it show short- or long-term intake rate-maximization? Journal of Animal Ecology 79: 53-62. https://doi.org/10.1111/j.1365-2656.2009.01608.x.

Rogers, D. I. 2003. High-tide roost choice by coastal waders. Bulletin-Wader Study Group 100: 73-79. 
Rogers, D. I., P. F. Battley, T. Piersma, J. A. Van Gils, and K. G. Rogers. 2006. High-tide habitat choice: Insights from modelling roost selection by shorebirds around a tropical bay. Animal Behaviour 72: 563-575. https://doi.org/10.1016/j.anbehav.2005.10.029.

Rohweder, D. A. 2001. Nocturnal roost use by migratory waders in the Richmond River Estuary, northern New South Wales, Australia. Stilt: 23-28.

Rojas, L. M., R. McNeil, T. Cabana, and P. Lachapelle. 1999. Diurnal and nocturnal visual capabilities in shorebirds as a function of their feeding strategies. Brain, Behavior and Evolution 53: 29-43. https://doi.org/10.1159/000006580.

Rompré, G., and R. McNeil. 1996. Variability in day and night feeding habitat use in the Willet Catoptrophorus semipalmatus during the non-breeding season in northeastern Venezuela. Wader Study Group Bull: 82-87.

Rosa, S., A. L. Encarnação, J. P. Granadeiro, and J. M. Palmeirim. 2006. High water roost selection by waders: Maximizing feeding opportunities or avoiding predation? Ibis 148: 88-97. https://doi.org/10.1111/j.1474-919X.2006.00497.x.

Santos, C. D., A. C. Miranda, J. P. Granadeiro, P. M. Lourenço, S. Saraiva, and J. M. Palmeirim. 2010. Effects of artificial illumination on the nocturnal foraging of waders. Acta Oecologica 36: 166-172. https://doi.org/10.1016/j.actao.2009.11.008.

Schmaltz, L., G. Quaintenne, L. Couzi, and J. Dupuy. 2019. Comptage des oiseaux d'eau à la mi-janvier en France. Résultats 2019 du comptage Wetlands International. LPO.

Schuler, K. L., G. M. Schroeder, J. A. Jenks, and J. G. Kie. 2014. Ad hoc smoothing parameter performance in kernel estimates of GPS-derived home ranges. Wildlife Biology 20: 259-266. https://doi.org/10.2981/wlb.12117.

Sitters, H. P., P. M. Gonzalez, T. Piersma, A. J. Baker, D. J. Price, H. P. Sitters, P. M. González, A. J. Baker, and D. J. Price. 2001. Day and night feeding habitat of red knots in Patagonia: Profitability versus safety? Journal of Field Ornithology 72: 8695. https://doi.org/10.1648/0273-8570-72.1.86.

Sitters, H. P. 2000. The role of night-feeding in shorebirds in an estuarine environment with specific reference to mussel-feeding Oystercatchers. University of Owford.

Smith, K. W., J. M. Reed, and B. E. Trevis. 1999. Nocturnal and diurnal activity patterns and roosting sites of green sandpipers Tringa ochropus wintering in southern England. Ringing \& Migration 19: 315-322. https://doi.org/10.1080/03078698.1999.9674200.

Stephens, D., and J. R. Krebs. 1986. Foraging theory. Vol. 1. Princeton University Press. https://doi.org/10.2307/1381654.

Thomas, K., R. G. Kvitek, and C. Bretz. 2003. Effects of human activity on the foraging behavior of sanderlings Calidris alba. Biological Conservation 109: 67-71. https://doi.org/10.1016/S0006-3207(02)00137-4.

Triplet, P., S. Le Dréan Quénec'hdu, and R. Mahéo. 2010. La Barge rousse Limosa lapponica hivernant en France (1977-2009). Alauda 78: 207-216.

Turpie, J. K., and P. a. R. Hockey. 1993. Comparative diurnal and nocturnal foraging behaviour and energy intake of premigratory grey plovers Pluvialis squatarola and whimbrels Numenius phaeopus in South Africa. Ibis 135: 156-165. https://doi.org/10.1111/j.1474-919X.1993.tb02827.x.

Van Winkle, W. 1975. Comparison of several probabilistic home-range models. The Journal of Wildlife Management: 118-123. https://doi.org/10.2307/3800474.

VanDusen, B. M., S. R. Fegley, and C. H. Peterson. 2012. Prey distribution, physical habitat features, and guild traits interact to produce contrasting shorebird assemblages among foraging patches. PloS One 7. https://doi.org/10.1371/journal.pone.0052694.

West, A. D., J. D. Goss-Custard, S. E. A. Le V. dit Durell, and R. A. Stillman. 2005. Maintaining estuary quality for shorebirds: Towards simple guidelines. Biological Conservation 123: 211-224. https://doi.org/10.1016/j.biocon.2004.11.010. 
679 Worton, B. J. 1989. Kernel methods for estimating the utilization distribution in home-range studies. Ecology 70: 164-168. https://doi.org/10.2307/1938423.

681 Zharikov, Y, and G. Skilleter. 2003. Depletion of benthic invertebrates by bar-tailed godwits Limosa lapponica in a subtropical estuary. Marine Ecology Progress Series 254: 151162. https://doi.org/10.3354/meps254151.

684 


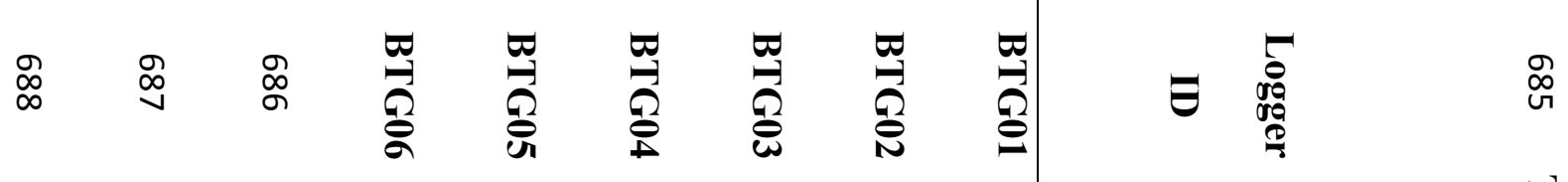

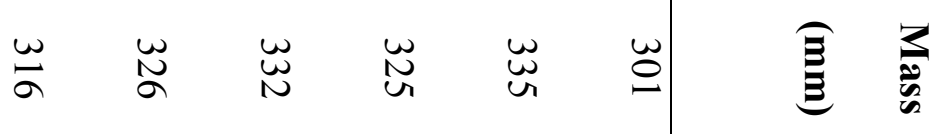

$\frac{\sqrt{2}}{\frac{2}{2}}$

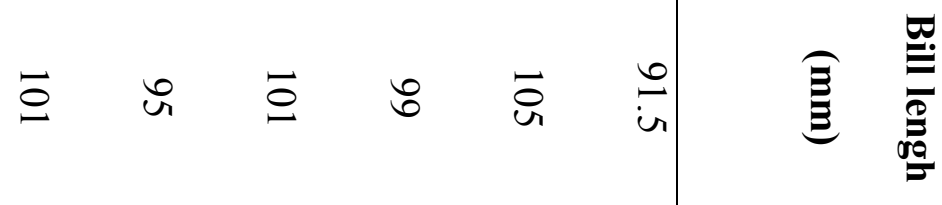

冡.

○

芑

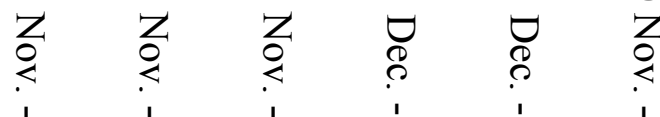

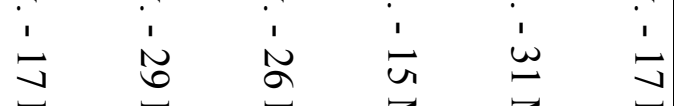

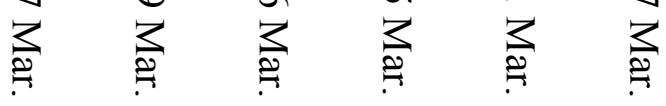

$\vec{\omega} \quad \vec{\omega} \quad \vec{\omega} \quad \vec{\triangleright} \quad \& \quad \vec{\infty}$

ᄅ.

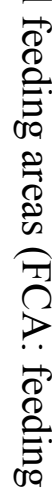

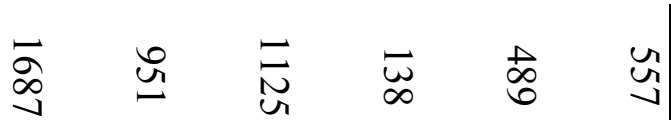

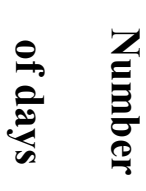

章

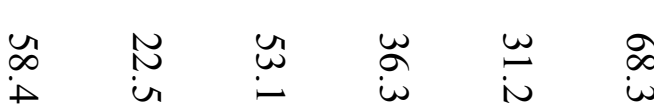

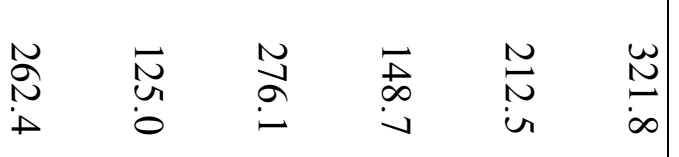

赵

冚

률

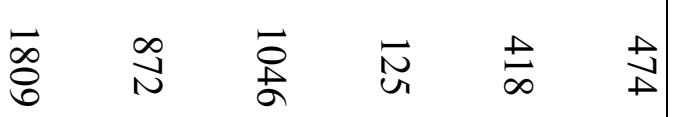

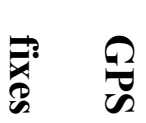

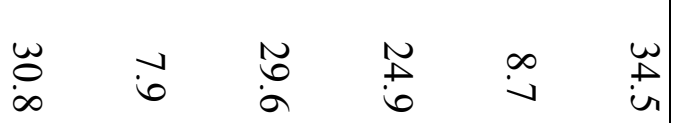

言

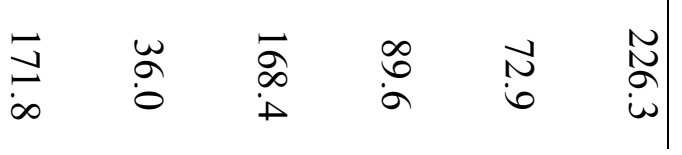

言竞

0
0
0
2
2
2

$\stackrel{8}{\circ}$

ส

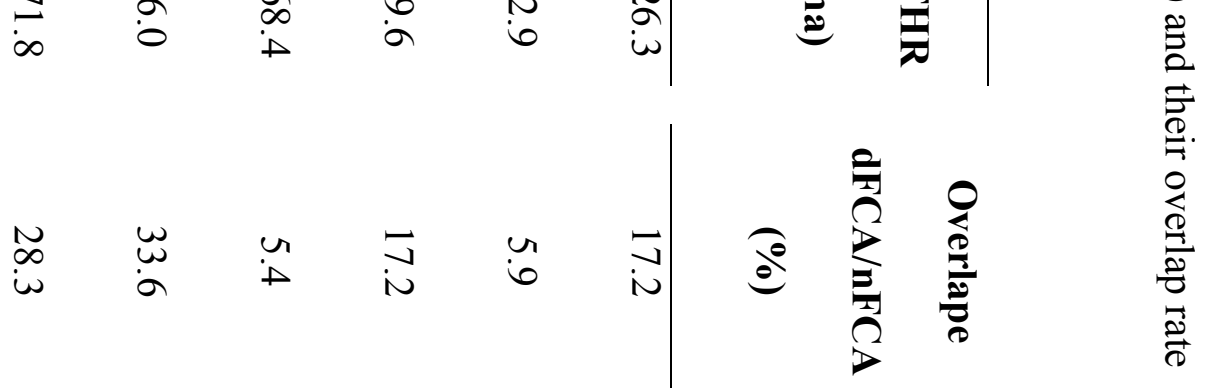

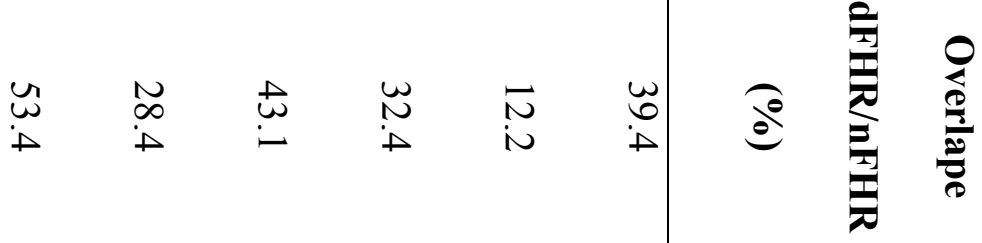




\section{Figure captions}

Fig. 1 Map of the Pertuis Charentais (Central French Atlantic coast) and localization of the study areas on Ré Island. Dark gray corresponds to the mainland and light gray to the intertidal area

Fig. 2 Diurnal and nocturnal feeding home ranges of six bar-tailed godwits during the nonbreeding period on Ré Island. Feeding home ranges were calculated as 50\% (core areas) and 95\% (home ranges) kernel density contours

Fig. 3 Mean proportion of time spent by six Bar-tailed godwits on mudflats, i.e. foraging, by day and by night during the tide cycle. Significant differences between Day and Night, for each slot time around the low tide, are illustrated by the symbols '*' when $\mathrm{p}<0.05$ and '***' when $\mathrm{p}<0.001$

Fig. 4 Day and night distribution of distances between two successive locations (30 min.)

Fig. 5 Habitat typology at (a) Ré Island, (b) "La Loge," and (c) "Fier d'Ars"

Fig. 6 Day and night proportion of habitat types on feeding core areas (50\% kernel density contour) of each bar-tailed godwit

Fig. 7 Results of the selection ratio analysis highlighting habitat selection by six bar-tailed godwits on 10 intertidal habitat types by (a) daytime and (b) nighttime

Fig. 8 Diurnal and nocturnal roosting home ranges of six bar-tailed godwits during the nonbreeding period on Ré Island. Roosting home ranges were calculated as 50\% (core areas) and 95\% (home ranges) kernel density contours 